\title{
ERRATUM
}

David A. Westcott $\cdot$ Joan Bentrupperbäumer

Matt G. Bradford · Adam McKeown

\section{Incorporating patterns of disperser behaviour into models of seed dispersal and its effects on estimated dispersal curves}

Published online: 15 December 2005

(C) Springer-Verlag 2005

\section{Oecologia (2005). DOI: 10.1007/s00442-005-0178-1}

Unfortunately, Fig. 2 was published without its legend. The figure appears here with the legend.

The online version of the original article can be found at http:/ dx.doi.org/10.1007/s00442-005-0178-1

D. A. Westcott $(\square) \cdot$ M. G. Bradford · A. McKeown CSIRO sustainable Ecosystem and the rainforest CRC, PO Box 780, Atherton, Q4883 Australia

E-mail: david.westcott@csiro.au

Tel.: + 61-7-40918827

Fax: $+61-7-40918888$

J. Bentrupperbäumer

Department of Tropical Environmental Science and Geopgraphy and the Rainforest CRC, Jamas Cook University, Cairns, Australia

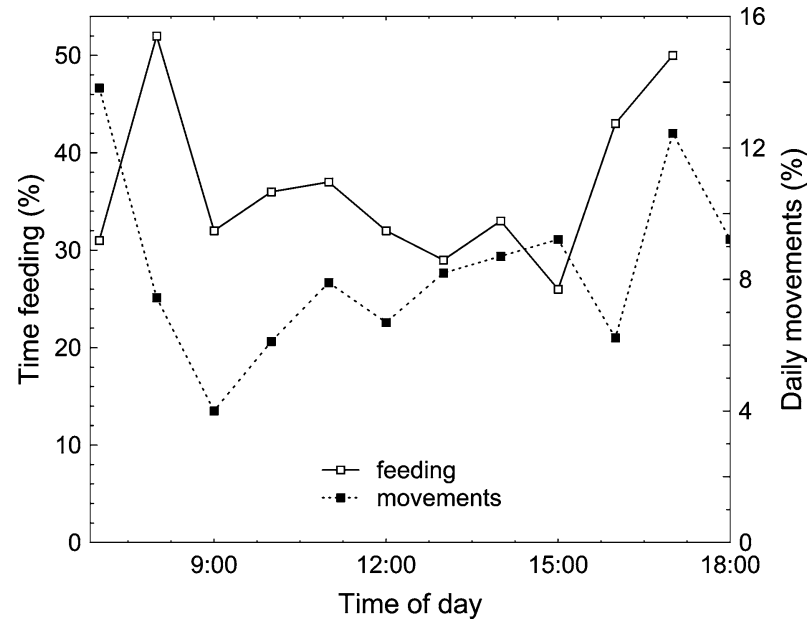

Fig. 2 Distribution of foraging effort and movement by $C$. casuarius throughout the day. Foraging effort was derived from direct observation of wild birds; movement $\%$ is the percentage of daily movement bouts that occur in each $60 \mathrm{~min}$ period, derived from radio-telemetry 